\title{
AJA WERA, ANTARA LARANGAN DAN TUNTUNAN
}

\author{
Oleh: \\ I Gusti Ketut Widana \\ Fakultas Pendidikan Agama dan Seni \\ Universitas Hindu Indonesia \\ Denpasar \\ igustiketutwidana1805@gmail.com
}

\begin{abstract}
The Hindus are known to be obedient and disciplined in considering the religious teachings as their code of conduct, especially related to the ritual practices (yadnya). So that, although they do not master the foundation of tattwa-jnana, the theology and the philosophy, they still feel firm and full of faith in carrying out their ritual obligations. The cause is its adherence to the adagium of 'gugon tuwon', which is usually accompanied by jargon 'nak mulo keto' (it is the way it is). So that the people live in carrying out the ritual obligations without having to ask the basis of truth. Consequently, most Hindus are relatively "awidya" (lack of knowledge) in terms of understanding the tattwa (philosophy), but discipline in terms of carrying out rituals (ceremonies). The common condition of knowledge is getting stronger with the presence of Aja Wera. This term is understood as a prohibition to learn or explore the religious teachings. If this warning is violated, it is said that it will cause people to be "inguh" (upset, anxious), which if allowed for a long time can get "buduh" (crazy). In fact, if understood, the Aja Wera implies a learning concept that provides guidance to the Hindus that if they study the religious teachings they are obliged to not get misunderstood or arrogant because they feel they are good at mastering the religious teachings. This is the dilemmatic condition of the concept of the Aja Wera, which lies between prohibitions and guidance.
\end{abstract}

Keywords: Aja Wera, prohibition, guidance

\begin{abstract}
Abstrak
Umat Hindu dikenal taat dan disiplin dalam menjalankan ajaran agamanya, terutama yang berkaitan dengan ritual (yadnya). Sehingga, walaupun relatif tidak menguasai landasan tattwajnananya, seperti teologi dan filosofinya, umat Hindu merasa mantap dan penuh keyakinan melaksanakan kewajiban ritualnya. Penyebabnya adalah kepatuhannya pada adagium 'gugon tuwon', yang biasanya disertai anak kalimat 'nak mulo keto' (memang sudah demikian adanya). Sehingga umat tinggal melaksanakan kewajiban ritual itu tanpa perlu bertanya apalagi mempertanyakan landasan kebenarannya. Konsekuensinya, kebanyakan umat Hindu relatif "awidya" (awam pengetahuan) dalam hal pemahaman tattwa (filsafat), tetapi disiplin dalam hal melaksanakan ritual (upacara). Kondisi keawaman pengetahuan itu semakin ajeg dengan adanya sesanti Aja Wera, yang dipahami sebagai bentuk "larangan" mempelajari atau mendalami ajaran agama. Jika larangan itu dilanggar, konon katanya akan menyebabkan orang bisa "inguh" (galau), yang apabila dibiarkan lama-lama bisa "buduh" (gila). Padahal, jika diselami sejatinya Aja Wera itu adalah konsep pembelajaran yang memberikan tuntunan kepada umat Hindu bahwa jika belajar atau mendalami ajaran agama diwajibkan untuk tidak mabuk atau sombong lantaran merasa telah pintar menguasai ajaran agama. Inilah kondisi dilematis konsep Aja Wera, berada di anatara larangan dan tuntunan.
\end{abstract}

Kata kunci: Aja wera, larangan, tuntunan 


\section{PENDAHULUAN}

Tidak dapat dimungkiri, pengetahuan, pengertian dan pemahaman umat Hindu kebanyakan tentang isi kitab-kitab suci, terutama Weda relatif jauh dari memadai. Apalagi sebagian besar praktik keagamaan umat Hindu lebih cenderung bahkan dominan bergerak di tingkatan ritual, sehingga menjadi terabaikan pentingnya peningkatan intelektual (tattwa) umat melalui proses pembelajaran guna mengetahui, mengerti dan memahami isi kandungan Weda.

Hal ini sejalan dengan pandangan Puspa (2015 : 229) yang menyatakan, bahwa dalam menjalankan ajaran agamanya umat Hindu di Bali umumnya melalui jalan karma dan bhakti sehingga penekanannya dalam bentuk ritual dan simbolik dibandingkan dengan pemahaman dan pengetahuan serta filsafat agama. Dengan demikian agama Hindu oleh banyak pihak dipandang sebagai agama yang lebih menekankan pada bentuk ekspresif dibandingkan dengan agama dalam makna pengetahuan/filsafat (jnana/tattwa).

Padahal menurut Donder (2013: 513) "sebenarnya ritual itu hanya alat dan bukan tujuan akhir manusia yang adalah realisasi diri, yaitu persatuan dengan Tuhan. Ritual memang bagian penting dari agama, sehingga bertahan begitu lama, namun banyak orang masih salah mengerti ritual Hindu; dan kesalahpahaman ini disebabkan oleh ketidaktahuan mereka terhadap ritual, mereka tidak pernah ingin mengetahui dengan benar tentang ritual tersebut".

Belum lagi adanya adagium "gugon tuwon anak mulo keto", yang seakan mendoktrin umat untuk tidak perlu belajar tentang Weda, atau pustaka suci lainnya. Umat cukup menggugu lalu meniru apapun ajaran atau tuntunan yang selama ini sudah diwariskan dari kalangan pendahulu sebagai warisan pelajaran yang tinggal melaksanakan saja tanpa perlu mempelajari atau banyak bertanya apalagi mempertanyakannya.

Keengganan umat mempelajari Weda atau kitab-kitab suci lainnya juga karena ada anggapan bahwa urusan mengetahui, mengerti dan memahmi kandungan isi Weda adalah porsinya kaum Brahmana yang dalam konteks Catur Warna, apalagi Catur Wangsa dikenal sekaligus dianggap sebagai golongan yang memahami bidang kerohanian/keagamaan. Apakah itu menyangkut pengetahuan tentang kandungan isi Weda, ucapan doa mantra, dan terutama menyangkuthal-hal yang berhubungan dengan pelaksanaan ritual yadnya. Semuanya sudah lumrah menjadi "kewenangan" sekaligus "keahlian" wangsa Brahmana yang di Bali dikenal sebagai kalangan "geriya" selaku Siwa sakala (Tuhan mendunia).

Disinilah letak persoalannya, mengapa umat Hindu pada umumnya enggan bahkan boleh dikatakan malas untuk belajar menekuni, mendalami apalagi mengkaji kandungan kitab suci Hindu dengan segala jenisnya, apakah Sruti, Smrti, Upaweda, Wedangga, Itihasa, Purana, dan seterusnya. Kondisi demikian ini, menyebabkan posisi adagium Aja Wera menjadi dilematis, berada di antara "larangan" ataukah "tuntunan".

\section{PEMBAHASAN}

Mengacu pandangan Pierre Bourdieu (19302002), salah satu modal besar yang dimiliki umat Hindu (Bali) adalah modal simbolik. Modal simbolik meliputi segala bentuk prestise, status, otoritas dan legitimasi. Khusus terkait dengan legitimasi, modal simbolik, merupakan upaya melestarikan dan meningkatkan pengakuan sosial melalui reproduksi skema-skema persepsi yang paling cocok hingga menghasilkan tindakan-tindakan simbolik yang bahkan kemudian diwarisi turun temurun. Salah satu modal simbolik dimaksud adalah adagium "ajya wera" (haywa/avwa wera, ajya wera, aja wera), yang dalam bahasa Jawa sepertinya sepadan dengan kata "ojo dumeh". Artinya kurang lebih: "jangan mabuk" atau "jangan sombong", setelah mempelajari atau menguasai sesuatu, bisa pelajaran/pengetahuan, kemampuan, kelebihan, keunggulan, atau kekuatan (Widana, 2019: 33).

Sebagaimana lazimnya, setiap agama memiliki kitab suci. Hindu sebagai agama tertua juga memiliki, mengakui dan meyakini kebenaran kitab sucinya yaitu Veda). Kata "Veda" itu sendiri berasal dari urat kata "Vid" yang berarti "pengetahuan". Sebagai pengetahuan, keberadaan Weda, tentu logikanya wajib diketahui dengan cara mempelajarinya. Tanpa proses belajar, apapun pengetahuan itu, entah pengetahuan duniawi (material) ataupun pengetahuan rohani (spiritual) jelas tidak akan 
dapat diketahui, dimengerti, dipahami, didalami apalagi hendak dikuasai. Diperlukan hasrat, niat dan semangat belajar untuk menguasai berbagai macam pengetahuan agama, seperti disuratkan di dalam penggalan Sarasamuscaya, sloka 177 : "nihan pajara mami, phala sang hnyang wedan inaji......, inilah yang hendak saya beritahukan, bahwa guna kitab weda adalah untuk dipelajari (Pudja, 1981: 97).

\section{Aja Wera, sebagai Larangan Belajar Agama?}

Swami Siwananda menyatakan bahwa Weda Sruti itu bersifat Prabhu Samhita yaitu kumpulan Mantra yang sangat berwibawa. Karena itu Mantra Weda Sruti tidak mudah dicapai oleh umat kebanyakan. Karena itu para Resi menyusun rumusan yang lebih mudah dipelajari oleh semua umat. Rumusan yang lebih mudah dan ramah itu disebut Suhrita Samhita. Dari konsep inilah muncul penjabaran ajaran Weda Sruti menjadi Smrti, Sila dan Acara. Tujuan akhirnya mencapai Atmanastusti yaitu kebahagiaan rokhani yang tertinggi.

Boleh jadi karena sifatnya yang berwibawa dengan segala rahasia di dalamnya, menjadikan setiap orang tidak dengan mudah "diizinkan" belajar agama melalui Weda, termasuk kandungan ajaran, ucap mantra dan sebagainya. Rupanya dari sini kemudian muncul gugon tuwon yang dikenal dengan istilah Aja Wera, yang memang acapkali dijumpai di dalam kitab/ pustaka suci, apalagi dalam lontar-lontar yang banyak disakralkan (keramat/tenget). Fatalnya, piteket Aja Wera yang merupakan adagium gugon tuwon itu justru kemudian seringkali dikonotasikan sebagai bentuk "larangan" belajar agama (kerohanian/spiritual), bahkan lengkap dengan berbagai "tekanan/ancaman", diantaranya bisa membuat orang pusing (puruh), galau (inguh) lalu gila (buduh).

Padahal jika dicermati, yang namanya gugon tuwon intinya adalah mengandung makna agar menggugu (memercayai) nasihat (piteket) lalu meniru hal-hal yang telah diwarisi melalui orang tua (anak tuha, nak tua, wong tuwo, tuwon), tanpa harus banyak bertanya lagi. Umat tinggal melaksanakan saja sebagai bentuk "imperatif" (perintah) orang yang dituakan (disebut juga anak lingsir), dan tidak usah menyanggah ataupun membantah. Sebab sebagai Guru Rupaka (orang tua) apalagi ajaran yang berasal leluhur (Pitara/Bhatara), apapun yang dinasihati/diajarkan sudah diyakini benar adanya. Asumsinya, tidak mungkin orang tua atau leluhur memberikan nasihat, petuah (piteket) atau ajaran salah yang bisa menyesatkan jalan pikiran, atau bahkan jalan kehidupan anak-anaknya (prati sentana).

Akan tetapi memori tentang gugon tuwon Aja Wera yang telah turun temurun dipahami sebagai bentuk larangan belajar agama ini rupanya hingga memasuki era Revolusi 4.0 ini tetap memenjarakan umat Hindu untuk terus berdiam diri alias belum bergerak ke arah pembelajaran agama. Terkesan umat Hindu pada umumnya bersikap masa bodoh dengan 'kebodohannya' sendiri, karena merasa tidak perlu atau malah menganggap tidak penting mempelajari, mengetahui, memahami, menghayati, apalagi mendalami serta menguasai hal-hal yang berkaitan dengan pengetahuan/ ajaran agama, yang sebagian diantaranya memang bersifat esoteris (rahasia). Alasan klasiknya, untuk apa mempelajari ajaran agama, bukankah sudah ada kelompok yang secara tradisional konservatif yaitu golongan wangsa Brahmana yang membidangi sekaligus menguasai perihal tattwa-jnana beragama, lebih-lebih tentang pelaksanaan upacara dan upakara yadnya dengan berbagai jenis, bentuk, fungsi, makna dan tingkatannya.

Sejatinya, dengan merujuk kitab Yajur Weda XVI. 18 sangat jelas dinyatakan bahwa kitab suci Weda memang patut diketahui atau dipahami oleh semua golongan umat Hindu :

Yathenam wacam kalyaman

Awadani janebhyah

Brahma rajya nyabhyam

Sudraya caryaya ca sway a caranaya ca

\section{Arti bebasnya :}

Demikianlah semoga hamba dapat menyampaikan sabda suci (Weda) ini kepada masyarakat umum, kepada Brahmana, Ksatria, Waisya dan Sudra, kepada orang-orang hamba bahkan kepada orang-orang lain sekalipun

Jadi, mempelajari, memahami bahkan menguasai inti sari ajaran Weda sejatinya bukan hanya untuk golongan tertentu (Brahmana) saja tetapi untuk semua umat Hindu. Oleh karena itu, dalam era global dengan pengagungan 
rasional berbasis intelektual di tengah era mileneal, keberadaan konsep gugon tuwon Aja Wera ini penting sekali direinterpretasi lanjut reaktualisasi agar dapat mengadaptasi sesuai konteks kekinian dengan segala fenomena, dinamika, realita dan problematikanya. Bukan tidak mungkin, ajaran agama Hindu ke depannya, lebih-lebih di tengah era teknologi dan informasi digital, jangankan yang bersifat esoteris (rahasia), yang berisi tuntunan praktis dalam menjalankan kewajiban beragama pun bisa ditinggalkan, lebih khawatir lagi keyakinan Hindu sebagai agamanya bisa saja ditanggalkan. Bila dicermati dengan pemahaman mendalam, ternyata konsep Aja Wera secara implisit justru menstimulus umat agar bergiat mempelajari, mengkaji dan mendalami ajaran Hindu, baik yang berada di tataran pengetahuan agama tingkat tinggi (parawidya/nirwirti/niskala) maupun pengetahuan agama level bawah (aparawidya/prawrti/sakala).

Hanya saja, ketika umat hendak mempelajari, mengkaji dan mendalami bagian ajaran yang tergolong rahasia (rahasya jnana) diperlukan kehadiran/pendampingan dari sosok guru pembimbing (acarya) agar tidak salah dalam mencerna ataupun menafsirkan ajaran yang bisa saja menjerumuskannya pada kesesatan pikiran dan keyakinan. Begitupula manakala umat sudah mulai mengetahui, bisa memamahi dan mampu mendalami, selalu diingatkan untuk "aja wera" dalam arti tidak mabuk karena kepintaran atau sombong lantaran merasa sudah menguasai pengetahuan ajaran agama.

\section{Aja Wera, sebagai Bentuk Tuntunan}

Menjelaskan tentang konsep Aja Wera itu, Suyadnya (2006: 3) dalam bukunya berjudul "Aywa Wera dan Pemahamannya" menyatakan bahwa dalam kitab-kitab dan lontar-lontar yang memuat ajaran agama Hindu sering dijumpai kalimat pendek "aja wera" atau "aywa wera". Kalimat pendek ini adalah peringatan penulis yang artinya jangan diperluas. Maknanya agar dibatasi atau dirahasiakan. Tidak boleh diajarkan secara senonoh tanpa memperhatikan syarat-syaratnya yang dapat menyebabkan halhal yang tidak diinginkan. Jadi memang ada materi ajaran yang sangat rahasia dan patut dirahasiakan, sehingga ajaran-ajaran seperti itu kurang tepat diceramahkan di depan umum, tetapi bukan berarti tidak boleh dipelajari.
Jadi, telah terjadi salah paham sekaligus keliru interpretasi terhadap adagium gugon tuwon Aja Wera, yang secara turun temurun selalu dinyatakan sebagai "larangan", padahal hakikatnya adalah sebagai tuntunan manakala belajar mendalami ajaran agama (kerohanian/ spiritual) agar tidak menyesatkan pikiran dan tindakan, apalagi keyakinan. Hanya saja persoalannya kini, pada kenyataannya masyarakat Hindu di Bali, meskipun mereka dikenal sebagai umat yang taat dan displin dalam menjalankan ajaran agamanya, terutama ritual yadnya. Namun dalam hal hasrat apalagi semangat untuk mempelajari, mendalami lebihlebih menguasai tattwa-jnananya, seperti teologi dan filosofinya boleh dikatakan jauh dari memadai. Pegangan kunonya masih tetap bersikukuh memegang dan menjalani piteket 'gugon tuwon' yang biasanya disertai anak kalimat 'nak mulo keto' (memang sudah demikian adanya).

Pendek kata dapat ditegaskan bahwa konsep Aja Wera, bukan bentuk larangan melainkan semacam tuntunan bahwa bilamana hendak mempelajari, memahami, mendalami bahkan menguasai pengetahuan agama, termasuk yang masuk katagori rahasia, hendaknya menyiapkan diri dengan disiplin, tidak sombong, atau takabur, tetaplah bersikap rendah hati, jangan sekali-kali merasa diri bisa (pintar/pandai), berlakulah seperti ilmu padi, semakin berisi semakin merunduk (phdi.or.id>artikel> aja wera). Ternyata konsep Aja Wera memberikan tuntunan bahwa hal-hal yang dianggap keramat, sakral tidak boleh semabarangan diwacanakan, dibicarakan apalagi digembar-gemborkan. Belajar pengetahuan agama (kerohanian/ spiritual) yang disucikan, disakralkan, bahkan dikeramatkan (tengetin) hendaknya sungguhsungguh (seken), fokus (konsentrasi), rajin, rutin dan dispilin, agar tidak terjadi penyimpangan dalam proses dan hasil pembelajarannya. Jadi, jika dikaitkan konsep pendidikan kekinian, konsep Aja Wera dapat dikatakan sebagai model pembelajaran hinduistuik yang bersifat esoterik (rahasya jnana).

Konsep Aja Wera, secara implisit juga memberikan tuntunan bahwa mempelajari ajaran keagamaan tidaklah serupa dengan ilmu pengetahuan pada umumnya yang bersifat terbuka dan objektif, selain sisi subyektivitas keilmuannya. Pengetahuan keagamaan 
(kerohanian/spiritual), apalagi yang berkaitan dengan pemahaman Brahmawidya (teologi) lengkap dengan kandungan jnana-tattwanya tentunya banyak hal bersifat rahasia yang sebenarnya "hanya boleh diketahui dan dipahami oleh beberapa orang tertentu saja". Untuk menyampaikannya atau proses pembelajarannya tentu diperlukan model tersendiri yang dalam kaitan ini tiada lain konsep Aja Wera yang dapat diangkat sebagai model pembelajaran esoterik. Dimana dalam penerapannya diperlukan sosok guru (acarya) yang tidak saja pandai, pintar, cerdas (wikan) tetapi lebih penting dan utama lagi telah memiliki kematangan jiwa, kedewasaan berpikir dan kebijaksanaan hati agar melahirkan output peserta didik/siswa (sisya) yang benar-benar sadhu gunawan (arif, bijak, dan berguna).

Pentingnya diterapkan konsep Aja Wera sebagai tuntunan belajar esoterik ini mengingat agama Hindu dengan ajaran-ajarannya, selain ada yang tergolong esoterik (rahasia) yang disebut parawidya (pengetahuan tertinggi), juga sarat dengan rahasia (rahasya jnana), sehingga tidak boleh sembarangan mempelajarinya, kecuali dengan tuntunan/ bimbingan guru suci/spiritual. Gunanya untuk menghindari kesesatan, baik pikiran, ucapan, tindakan dan keyakinannya. Berbeda dengan pengetahuan ajaran agama Hindu yang termasuk aparawidya, umumnya berupa tuntunan hidup secara sakala di dunia nyata, tentunya tidak tergolong rahasia, karena akan digunakan sebagai pegangan/pedoman hidup sehari-hari dalam rangka mencapai tujuan hidup (catur purusa artha) : dharma, artha, kama dan moksa. Karena tidak merupakan rahasia, semua umat Hindu sepatutnya wajib mempelajari, mengetahui, memahami, mendalami bahkan menguasai, meskipun harus tetap bersikap rendah hati, tidak sombong dan berperilaku kegila-gilaan karena ilmu agama yang dimiliki.

\section{PENUTUP}

Berdasarkan deskripsi di atas, tampaknya konsep Aja Wera, meski tidak populer bahkan sampai saat ini maih dianggap sebagai bentuk "larangan" belajar pengetahuan agama, tetapi sesungguhnya dibalik konsep Aja Wera itu terkandung tuntunan agar umat, terutama ketika mempelajari pengetahuan agama, apalagi yang bersifat esoterik (rahasia) dan bahkan disakralkan (tenget/keramat), perlu menunjukkan sikap dan perilaku yang jauh dari kesombongan, atau mabuk karena penguasaan pengetahuannya lalu berperilaku seperti orang mabuk atau kegila-gilaan, yang sangat bertolak belakang dengan pitutur ayu "eda ngaden awak bisa, depang anake ngadanin".

Intinya, sebagaimana dikatakan Sandika (2011: 47) umat yang hendak belajar agama apalagi sebagai siswa (sisya) yang disebut kaum Brahmacarya, merupakan tahapan awal seorang manusia untuk mulai belajar. Tidak sekedar belajar dalam arti lumrah, tetapi "belajar" dalam artian mencari kesejatian diri, siapa diri kita, dari mana diri kita berasal, dan kemana kita setelah mati ? Atau dengan kata lain belajar memahami hakikat diri kita dan tujuan dari kehidupan ini sebenamya. Dapat pula dianalogikan, bahwa masa belajar (brahmacrya) ini sebagai fase pembelajaran pertama dan utama sekaligus proses pembekalan seseorang yang bagaikan melakukan perjalanan jauh nan panjang. Sehingga amat penting diberikan peta yang berisi gambaran kemana kakinya mesti melangkah dalam mencari dan mencapai tujuan hidupnya, moksartham jagadhita ya ca iti dharmah. 


\section{Daftar Pustaka}

Donder, I Ketut. 2013. “Logical Interpretation of Some Performing Hindu Rituals”. Disertasi. Kolkata India: Rabhindra Bharati University

Pudja, G. 1981. Sarasamuscaya, teks dan terjemahannya. Jakarta: Proyek Pengadaan Kitab Suci Hindu Departemen Agama RI.

Puspa, Ida Ayu Tary. 2015. "Reinterpretasi Terhadap Efekitivitas Praktik Beragama Umat Hindu Di Bali". Artikel dalam Buku Konsep Dan Praktik Agama Hindu Di Bali, Oleh Tim Peneliti WHP/WHC. I Gede Suwantana (Ed.). Surabaya : Paramita

Sandika, I Ketut.. 2011. Pendidikan Menurut Veda: Sadhana Spiritual bagi Generasi Muda. Denpasar : Pustaka Bali Post.

Suyadnya, I Gusti Ngurah Made. 2006. Aywa Wera dan Pemahamannya. Surabaya : Paramita

Widana, I Gusti Ketut. 2019. “Konsep Aja Wera Sebagai Model Pembelajaran Esoterik Pada Umat Hindu Di Bali”. Dimuat pada E-Journal Widyanatya Vol 1 No 1, 2019.

phdi.or.id >artikel> aja wera 